\section{Tropical Journal of Pathology and Microbiology}

2021 Volume 7 Number 1 January-February

\title{
Study on specific species of malaria in relation to haematological changes
}

\author{
Kanaujia B. ${ }^{1}$, Anand A S. ${ }^{2}$, Mhetre S. ${ }^{*}$ \\ DOI: https://doi.org/10.17511/jopm.2021.i01.01
}

\footnotetext{
1 Binita Kanaujia, Senior Resident, Dr Hedgewar Arogya Santhan, New Delhi, India.

2 Anand A S, Professor and Head, Department of Pathology, Navodaya Medical College, Raichur, Karnataka, India.

3* Sagar Mhetre, Professor, Department of Pathology, Ashwini Rural Medical College, Hospital and Research Centre, Solapur, Maharashtra, India.
}

Background: As malaria is a potential medical emergency, prompt and accurate diagnosis is critical for its effective management. Conventional microscopic examination of peripheral thick and thin blood smear examination remains the "gold standard" for malaria diagnosis. Material: A 2 year prospective study from 2011 to 2013 was conducted at Navodaya Medical College Hospital and Research Centre, Raichur. The study comprised of a total number of 150 cases positive for Malaria, collected from above mentioned centre and those referred from peripheral referral centres. Clinical history regarding age, sex, nature and duration of illness were elicited. Blood sample for haematological study was taken before starting anti-malarial drugs in all these cases. Result: Out of total cases, P. vivax infected cases (62\%) were common than P. falciparum (34\%) and mixed infection cases [PV \& PF] (4\%). Most common presenting symptom of cases affected by PV, PF and mixed infection were fever and chills \& rigors and least common symptom was cough. Most important haematological changes observed were anaemia and thrombocytopenia (77.3\% each) and leucopenia (31.3\%). All the above mentioned changes in haematological parameters were species specific and statistically significant, except for red cell indices, DLC and ESR. Conclusions: In conclusion, changes in haematological profile can help in early diagnosis of specific species of malaria for timely and appropriate treatment that can reduce the severity and prevention of additional consequences.

Keywords: Haematological parameters, P. vivax, P. Falciparum, Mixed infection

Corresponding Author

Sagar Mhetre, Professor, Department of Pathology, Ashwini Rural Medical College, Hospital and Research Centre, Solapur, Maharashtra, India. Email: sagarmhetre@rediffmail.com

\section{How to Cite this Article}

Kanaujia B, Anand A S, Mhetre S. Study on specific species of malaria in relation to haematological changes. Trop J Pathol Microbiol. 2021;7(1):1-8. Available From https://pathology.medresearch.in/index.php/jopm/ar ticle/view/505
To Browse

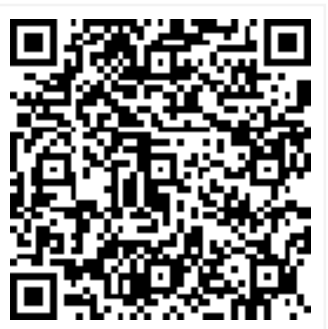

Manuscript Received 2020-12-15

Conflict of Interest No

Review Round 1
2020-12-25
Funding
Nil

Nil

Review Round 2
2021-01-04
Ethical Approval
Yes

Review Round 2

Yes

\section{Review Round 3 \\ Plagiarism X-checker $6 \%$}

Accepted 2021-01-30

Note 


\section{Introduction}

Mainly affected due to malaria infection are children, pregnant women (particularly primigravidae) and non immune people (e.g., travellers, foreign workers). However, all age groups may be at risk of severe disease during malaria epidemics, which occur either due to changes in the physical environment (caused by climatic variation, agricultural projects, mining, etc) which increase the capacity of mosquitoes to transmit the disease or during population displacements (natural disasters, war) which can expose non immune populations to this infection [1].

Irrespective of the type of malarial infection, multisystem involvement is seen importantly affecting renal, haematological, central nervous system, etc though the degree of involvement may vary and in some cases, adds to mortality.

Haematological abnormalities that have been reported include anaemia, thrombocytopenia, splenomegaly, mild to moderate atypical lymphocytosis and rarely, disseminated intravascular coagulation, while others documented are neutropenia, eosinophilia, neutrophilia and monocytosis [2-9].

As malaria is a potential medical emergency, prompt and accurate diagnosis is critical for its effective management. Conventional microscopic examination of peripheral thick and thin blood smear examination remains the "gold standard" for malaria diagnosis, which provides the most comprehensive information on a single test format.

The technique is widely accepted worldwide due to its simplicity, low cost, high specificity and ability to assess parasitic density and variations in haematological parameters can be of great help to support the diagnosis, as the target of malarial parasite is RBC [10-12].

Quick and convenient rapid diagnostic tests like fluorescent microscopy (QBC), dipstick antigen detection test (HRP-2 and PLDH based) and PCR assays are currently implemented, but are not cost effective and need improved quality control [10-13].

Haematological changes have been reported along with malaria include anemia, thrombocytopenia and leukocytosis, leukopenia, mild to moderate atypical lymphocytosis, , eosinophilia, neutrophilia and monocytosis [14-16].
Prediction of haematological changes enables the clinician to establish an effective and early therapeutic intervention, in order to prevent the occurrence of major complications and death [8]. Hence, this study is designed to assess haematological changes with respect to specific species of malaria.

\section{Materials and methods}

A 2 year prospective study from 2011 to 2013 was conducted at Navodaya Medical College Hospital and Research Centre, Raichur. The study comprised of a total number of 150 cases positive for Malaria, collected from above mentioned centre and those referred from peripheral referral centres.

\section{Selection criteria:}

Inclusion criteria: All the patients positive for Malaria and Patients of $>12$ yrs of age are included in the study

Exclusion criteria: Patients of $<12$ yrs of age, as there is refusal for blood sampling, Cases of Malaria with other infections and, Malaria diagnosed by alternate methods like rapid card test, QBC method, etc.

Data collection procedure: Clinical history regarding age, sex, nature and duration of illness were elicited. Blood sample for haematological study was taken before starting anti-malarial drugs in all these cases.

Venous blood was collected in EDTA Vacutainer (for Complete blood count) and $3.8 \%$ sodium citrate vacutainers (for ESR estimation).

Study of haematological profile in malaria was done evaluating parameters like Haemoglobin ( $\mathrm{Hb})$, Haematocrit (HCT), RBC indices like MCV (Mean corpuscular volume), $\mathrm{MCH}$ (Mean corpuscular haemoglobin), MCHC (Mean corpuscular haemoglobin concentration), TLC and platelet count, which were measured by automated haemoanalyzer.

Thin and thick blood smears were prepared using fresh blood sample stained with Leishman / Giemsa stain and was studied for presence of parasite, identification of plasmodium species and differential leucocytes count.

Statistical Analysis: Descriptive statistics were used such as percentage to present the haematological changes in patients of malaria. 
Relationship between the haematological changes with respect to specific species of malaria was calculated by chi-square test. A two-tailed p-value less than 0.05 were considered as significant and 0.01 as highly significant. Data was analysed by using software SPSS v20.0

\section{Result}

Table-1: Distribution of Malaria cases according to species.

\begin{tabular}{|l|l|l|}
\hline \multicolumn{1}{|c|}{ Malarial species } & No of Cases & Percentage (\%) \\
\hline P. Vivax & 93 & 62 \\
\hline P. Falciparum & 51 & 34 \\
\hline Mixed infection (PV \& PF) & 06 & 04 \\
\hline Total & 150 & 100 \\
\hline
\end{tabular}

Vivax infection (93 cases, 62\%) was most common followed by P. falciparum (62 cases, 34\%) and least was mixed infection (06 cases, 04\%), out of the total cases included in the study.

Table-2: Hb concentration \& severity of anaemia in PV, PF and mixed malarial infections

\begin{tabular}{|l|l|l|l|l|}
\hline Hb $(\mathrm{gm} / \mathrm{dl})$ & P.Vivax & P.Falciparum & Mixed infection & TOTAL (\%) \\
\hline$<5$ & $08(8.6 \%)$ & $20(39.3 \%)$ & $02(33.3 \%)$ & $30(20 \%)$ \\
\hline $5-8$ & $16(17.2 \%)$ & $19(37.2 \%)$ & $03(50 \%)$ & $38(25.3 \%)$ \\
\hline $8-11$ & $39(41.9 \%)$ & $09(17.7 \%)$ & & $48(32 \%)$ \\
\hline$>11$ & $30(32.2 \%)$ & $03(5.8 \%)$ & $01(16.6 \%)$ & $34(22.7 \%)$ \\
\hline TOTAL & 93 & 51 & 06 & $150(100 \%)$ \\
\hline
\end{tabular}

$\mathrm{X} 2=42.4, \mathrm{df}=3, \mathrm{p}<0.0001$, Significant association

Anaemia was a common feature in 116 cases $(77.3 \%)$ out of the total cases studied while 34 cases $(22.7 \%)$ of the cases had normal level of $\mathrm{Hb}$. In P. vivax infected cases, mild degree (39 cases, $41.9 \%$ ) of anaemia was predominant followed by moderate (16 cases, $17.2 \%$ ) and severe degree (08 cases, $8.6 \%$ ) of anaemia, whereas in P. falciparum infected cases, severe (20 cases, 39.3\%) and moderate degree (19 cases, $37.2 \%$ ) of anaemia was observed in most of the cases, followed by mild degree (09 cases, $17.7 \%$ ) and mixed infection cases exhibited mostly moderate (03 cases, 50\%) and severe degree (02 cases, $33.3 \%$ ) of anaemia. The association of anaemia and the species was statistically significant.

Table-3: relationship of rbc count with PV, PF and mixed malarial infections.

\begin{tabular}{|l|l|l|l|l|}
\hline RBC count & P. vivax & P. falciparum & Mixed infection & TOTAL (\%) \\
\hline
\end{tabular}

\begin{tabular}{|l|l|l|l|l|}
\hline NORMAL & $39(41.9 \%)$ & $09(17.6 \%)$ & $02(33.3 \%)$ & $50(33.4 \%)$ \\
\hline LOW & $50(53.8 \%)$ & $40(78.4 \%)$ & $04(66.6 \%)$ & $94(62.6 \%)$ \\
\hline
\end{tabular}

\begin{tabular}{|l|l|l|l|l|}
\hline HIGH & $04(4.3 \%)$ & $02(3.92 \%)$ & - & $06(04 \%)$ \\
\hline TOTAL & 93 & 51 & 06 & $150(100 \%)$ \\
\hline
\end{tabular}

$\mathrm{X} 2=11.1, \mathrm{df}=1, \mathrm{p}=0.0009$, Significant association

Decreased RBC count in the present study was seen in 94 cases $(62.6 \%)$ while 50 cases $(33.4 \%)$ of the total cases had normal count, out of total 150 cases. Low RBC count was seen more in P. falciparum infected cases (40 cases, 78.4\%) as compared to mixed infection (04 cases, 66.6\%) and P. vivax infected cases (50 cases, 53.8\%). The association between RBC count and species was strongly significant. However, few cases of $P$. vivax (04 cases, 4.3\%) and P. falciparum (02 cases, $3.92 \%$ ) also showed high RBC count.

Table-4: Relationship of HCT with PV, PF and mixed malarial infections.

\begin{tabular}{|l|l|l|l|l|}
\hline HCT \% & P. vivax & P. falciparum & Mixed infection & TOTAL (\%) \\
\hline NORMAL & $26(27.9 \%)$ & $02(3.9 \%)$ & & $28(18.7 \%)$ \\
\hline LOW & $63(67.8 \%)$ & $48(94.2 \%)$ & $06(100 \%)$ & $117(78 \%)$ \\
\hline HIGH & $04(4.3 \%)$ & $01(1.9 \%)$ & - & $05(3.3 \%)$ \\
\hline TOTAL & 93 & 51 & 06 & $150(100 \%)$ \\
\hline
\end{tabular}

$\mathrm{X} 2=17.01, \mathrm{df}=1, \mathrm{p}<0.0001$, Significant association

A fall in hematocrit was observed in 117 cases $(78 \%)$ of the total 150 cases in this study, whereas normal levels were seen in 28 cases (18.7\%). Low values were more profound among the P. falciparum infected cases (48 cases, 94.2\%) when compared to P. vivax cases (63 cases, 67.8\%) whereas, all cases of mixed infection (06 cases, 100\%) had low hematocrit. The association between HCT and species was strongly significant. Few cases of $P$. vivax (04 cases, 4.3\%) and P. falciparum (01 case, $1.9 \%$ ) also showed high hematocrit.

Table-5: Relationship of MCV with PV, PF and mixed malarial infections.

\begin{tabular}{|l|l|l|l|l|}
\hline \multicolumn{1}{|c|}{ MCV } & \multicolumn{1}{c|}{ P. vivax } & P. falciparum & Mixed infection & TOTAL (\%) \\
\hline NORMAL & $42(45.1 \%)$ & $31(60.7 \%)$ & $02(33.3 \%)$ & $75(50 \%)$ \\
\hline LOW & $43(46.2 \%)$ & $17(33.3 \%)$ & $03(50 \%)$ & $63(42 \%)$ \\
\hline HIGH & $08(8.6 \%)$ & $03(5.8 \%)$ & $01(16.6 \%)$ & $12(08 \%)$ \\
\hline TOTAL & 93 & 51 & 06 & $150(100 \%)$ \\
\hline
\end{tabular}

$\mathrm{X}_{2}=2.303, \mathrm{df}=1, \mathrm{p}=0.32$, No significant association

MCV was decreased in 63 cases (42\%) whereas 75 cases $(50 \%)$ of the total cases showed normal values out of the total cases studied. Low MCV value was seen mostly in mixed infection cases (03 cases, $50 \%$ ) followed by P. vivax infected cases (43 cases, $46.2 \%$ ) and P. falciparum infected cases (17 cases, 
$33.3 \%$ ), and few cases (12cases, $8 \%$ ) also showed raised $\mathrm{MCV}$. There was no significant association statistically.

Table-6: Relationship of MCH with PV, PF and mixed malarial infections.

\begin{tabular}{|l|l|l|l|l|}
\hline \multicolumn{1}{|c|}{ MCH } & \multicolumn{1}{|c|}{ P. vivax } & P. falciparum & Mixed infection & TOTAL (\%) \\
\hline NORMAL & $50(53.7 \%)$ & $28(54.9 \%)$ & $03(50 \%)$ & $81(54 \%)$ \\
\hline LOW & $34(36.5)$ & $18(35.2 \%)$ & $02(33.3 \%)$ & $54(36 \%)$ \\
\hline HIGH & $09(9.6 \%)$ & $05(9.8 \%)$ & $01(16.6 \%)$ & $15(10 \%)$ \\
\hline TOTAL & 93 & 51 & 06 & $150(100 \%)$ \\
\hline
\end{tabular}

$X_{2}=0.05, d f=2, p=0.97$, No significant association

Low $\mathrm{MCH}$ values were seen 54 cases (36\%) and normal values were observed in 81 cases (54\%) of the total 150 cases. In P. vivax infected cases (34 cases, $36.5 \%)$, P. falciparum (18 cases, 35.2\%), and mixed infection ( 02 cases, 33.3\%) $\mathrm{MCH}$ values were almost low and equivalent, with no significant species specific statistical difference and high $\mathrm{MCH}$ values were seen in few cases of P. vivax (09 cases, 9.6\%) and P. falciparum (05 cases, 9.8\%).

Table-7: Relationship of MCHC with PV, PF and mixed malarial infections.

\begin{tabular}{|l|l|l|l|l|}
\hline MCHC & \multicolumn{1}{|c|}{ P. vivax } & P. falciparum & Mixed infection & TOTAL (\%) \\
\hline NORMAL & $59(63.4 \%)$ & $33(64.7 \%)$ & $04(66.6 \%)$ & $96(64 \%)$ \\
\hline LOW & $21(22.5 \%)$ & $10(19.6 \%)$ & $02(33.3 \%)$ & $33(22 \%)$ \\
\hline HIGH & $13(13.9 \%)$ & $08(15.6 \%)$ & & $21(14 \%)$ \\
\hline TOTAL & 93 & 51 & 06 & $150(100 \%)$ \\
\hline
\end{tabular}

$\mathrm{X} 2=0.05, \mathrm{df}=2, \mathrm{p}=0.97$, No significant association

MCHC values were low in 33 cases (22\%) and normal in 96 cases (64\%) of the total cases studied. Low MCHC was seen most in mixed infection (02 cases, 33\%) followed by P. vivax (21 cases, $22.5 \%$ ) and $P$. falciparum infected cases (10 cases, 19.6\%). There was no significant association statistically. Few P. vivax (13 cases, 13.9\%) and P. falciparum infected cases (08 cases, 15.6\%) also showed high $\mathrm{MCHC}$ values.

Table-8: Relationship of TLC with PV, PF and mixed malarial infections.

\begin{tabular}{|l|l|l|l|c|}
\hline \multicolumn{1}{|c|}{$\begin{array}{c}\text { WBC } \\
\text { Count }(/ \mathrm{mm} 3)\end{array}$} & P.vivax & $\begin{array}{c}\text { P.falciparu } \\
\mathbf{m}\end{array}$ & $\begin{array}{c}\text { Mixed } \\
\text { infection }\end{array}$ & $\begin{array}{c}\text { TOTAL } \\
(\%)\end{array}$ \\
\hline$<4000$ & $\begin{array}{l}21 \\
(22.5 \%)\end{array}$ & $24(47.1 \%)$ & $02(33.3 \%)$ & $47(31.3 \%)$ \\
\hline $4000-11,000$ & 64 & $23(45.1 \%)$ & $03(50 \%)$ & $90(60 \%)$ \\
\hline$>11,000$ & $08(8.6 \%)$ & $04(7.8 \%)$ & $01(16.7 \%)$ & $13(8.7 \%)$ \\
\hline TOTAL & 93 & 51 & 06 & $150(100 \%)$ \\
\hline
\end{tabular}

$\mathrm{X} 2=9.16, \mathrm{df}=2, \mathrm{p}=0.01$, Significant association
Leucopenia was seen in 47 cases $(31.3 \%)$ of the total 150 cases among which, it was more common in P. falciparum infected cases (24 cases, 47.1\%) followed by mixed infection (02 cases, 33.3\%) and P. vivax infected cases (21 cases, 22.5\%). There was a significant statistical association. Normal leucocyte count was seen in 90 cases $(60 \%)$ out of the total cases, whereas 13 cases $(8.7 \%)$ showed leucocytosis.

Table-9: Relationship of DLC with PV, PF and mixed malarial infections.

\begin{tabular}{|l|l|l|l|l|}
\hline \multicolumn{1}{|c|}{ DLC } & P. vivax & P. falciparum & Mixed infection & TOTAL (\%) \\
\hline NEUTROPHILIA & $10(10.7 \%)$ & $06(11.7 \%)$ & $01(16.6 \%)$ & $23(15.3 \%)$ \\
\hline NEUTROPENIA & $31(33.3 \%)$ & $33(64.7 \%)$ & & $64(42.6 \%)$ \\
\hline LYMPHOCYTOSIS & $03(3.2 \%)$ & $10(19.6 \%)$ & $01(16.6 \%)$ & $14(9.3 \%)$ \\
\hline LYMPHOPENIA & $10(10.7 \%)$ & $17(33.3 \%)$ & $01(16.6 \%)$ & $28(18.7 \%)$ \\
\hline EOSINOPHILIA & $13(14 \%)$ & $06(11.7 \%)$ & $01(16.6 \%)$ & $20(13.3 \%)$ \\
\hline MONOCYTOSIS & $18(19.3 \%)$ & $09(17.6 \%)$ & $01(16.6 \%)$ & $28(18.7 \%)$ \\
\hline
\end{tabular}

$\mathrm{X} 2=1.42, \mathrm{df}=2, \mathrm{p}=0.49$, No significant association

Neutrophilia was observed in 23 cases (15.3\%) of the total 150 cases, which was seen most among cases of mixed infection (01 case, 16.6\%) followed by $P$. falciparum

(06 cases, $11.7 \%$ ) and P. vivax infected cases (10 cases, $10.7 \%)$.

Neutropenia was observed in 64 cases $(42.6 \%)$ of the total cases, mostly in P. falciparum infected cases (33 cases, 64.7\%) followed by P. vivax infected cases (31 cases, 33.3\%) and none was seen in mixed infection.

Lymphocytosis was seen in 14 cases (9.3\%) of the total 150 cases, mostly in P. falciparum infected cases (10 cases, $19.6 \%$ ) followed by mixed infection (01 cases, $16.6 \%$ ) and P. vivax infected case (03 cases, 3.2\%). Lymphopenia was seen in 28 cases $(18.7 \%)$ of the total cases, mostly in P. falciparum infected cases (17 cases, 33.3\%) followed by mixed infection (01 case, 16.6\%) and P. vivax infected cases (10 cases, $10.7 \%$ ).

Eosinophilia was seen in 20 cases $(13.3 \%)$ of the total cases, mostly in mixed infection case (01 case, $16.6 \%$ ) followed by P. vivax (13 cases, 14\%) and P. falciparum infected cases (06 cases, 11.7\%).

Monocytosis was observed in 28 cases (18.7\%) of the total cases, mostly in P. vivax (18 cases, $19.3 \%$ ) followed by $P$. falciparum infected cases (09 cases, $17.6 \%$ ) and mixed infection cases (01 case, $16.6 \%)$. 
There was no much species specific variation in eosinophil and monocyte count.

Table-10: Relationship of platelet count with PV, PF and mixed malarial infections.

\begin{tabular}{|l|l|l|l|l|}
\hline Platelet count (/mm3) & P. vivax & $\begin{array}{c}\text { P. } \\
\text { falciparum }\end{array}$ & $\begin{array}{c}\text { Mixed } \\
\text { infection }\end{array}$ & $\begin{array}{l}\text { TOTAL } \\
(\%)\end{array}$ \\
\hline $\begin{array}{l}\text { MILD(1.5lakhs- } \\
50,000 / \mathrm{mm} 3)\end{array}$ & $\begin{array}{l}29 \\
(31.2 \%)\end{array}$ & $13(25.5 \%)$ & $01(16.6 \%)$ & $\begin{array}{l}43 \\
(28.7 \%)\end{array}$ \\
\hline $\begin{array}{l}\text { MODERATE(50,000- } \\
20,000 / \mathrm{mm} 3)\end{array}$ & $\begin{array}{l}32 \\
(34.4 \%)\end{array}$ & $13(25.5 \%)$ & $04(66.6 \%)$ & 49 \\
\hline SEVERE $(<20,000 / \mathrm{mm} 3)$ & 09 & $14(27.5 \%)$ & $01(16.7 \%)$ & $24(16 \%)$ \\
\hline NORMAL( $>1.5$ & $9.1 \%)$ & & & \\
lakhs/mm3) & $23(24.7$ & $11(21.5 \%)$ & - & 34 \\
\hline TOTAL & $\%)$ & & & $(22.7 \%)$ \\
\hline
\end{tabular}

$\mathrm{X}_{2}=8.62, \mathrm{df}=3, \mathrm{p}=0.035$, Significant association

Thrombocytopenia was observed in 116 cases $(77.4 \%)$ of the total 150 cases. In P. vivax infected cases, moderate degree of thrombocytopenia ( 32 cases, $34.4 \%$ ) was common, followed by mild ( 29 cases, $31.2 \%$ ) and severe degree (09 cases, 9.1\%), whereas in P. falciparum infected cases severe degree ( 14 cases, $27.5 \%$ ) was common, followed by mild (13 cases, $25.5 \%)$ and moderate degree (13 cases, $25.5 \%$ ) of thrombocytopenia and in cases of mixed infection, moderate (04 cases, 66.6\%) and severe degree (01 cases, $16.7 \%$ ) thrombocytopenia was common followed by mild degree (01 case, $16.6 \%$ ) of thrombocytopenia. There was significant association statistically between species of malaria and degree of thrombocytopenia. Normal platelet count was observed in 34 cases $(22.7 \%)$ of the total cases.

Table-11: Relationship of ESR with PV, PF and mixed malarial infections.

\begin{tabular}{|l|l|l|l|l|}
\hline \multicolumn{1}{|c|}{ ESR } & \multicolumn{1}{c|}{ P. vivax } & P. falciparum & Mixed infection & TOTAL (\%) \\
\hline MILD & $29(31.1 \%)$ & $14(27.4 \%)$ & $02(33.3 \%)$ & $45(30 \%)$ \\
\hline MODERATE & $48(51.6 \%)$ & $23(45.1 \%)$ & $03(50 \%)$ & $74(49.3 \%)$ \\
\hline SEVERE & $08(8.6 \%)$ & $10(19.6 \%)$ & $01(16.6 \%)$ & $19(12.6 \%)$ \\
\hline NORMAL & $08(8.6 \%)$ & $04(7.8 \%)$ & - & $12(08 \%)$ \\
\hline TOTAL & 93 & 51 & 06 & $150(100 \%)$ \\
\hline
\end{tabular}

$\mathrm{X} 2=3.67, \mathrm{df}=3, \mathrm{p}=0.29$, No significant association

In the present study, 138 cases (92\%) of the total 150 cases showed raised ESR and was mostly seen in mixed infection cases (06 cases, 100\%), followed by P. falciparum (47 cases, $92.1 \%$ ) and P. vivax infected cases (85 cases, $91.3 \%$ ). However, this difference was statistically not significant.
Few cases (12 cases, $08 \%$ ) of the total cases also showed normal ESR values.

\section{Discussion}

Different species: In the present study the cases infected with most common species of malaria was P. vivax (62\%) followed by P. falciparum (34\%) and mixed infection (4\%) and there was a good correlation when compared with the studies conducted by Chandra S and Erhart et al (P. Vivax$69.8 \%$ \& 59\%, P. Falciparum - 27.5\% \& 38\%, and mixed infection $-2.7 \% \& 2 \%)[17,18]$, whereas in studies conducted by Layla AM (P. Vivax-39\%, P. Falciparum - 54.2\% and mixed infection - 4.4\%) [2] and Rasheed A, P. (P. Vivax-19.9\%, P. Falciparum $-62 \%$ and mixed infection - 18.1\%) [6] falciparum was the most common species followed by $P$. vivax and mixed infection.

RBC COUNT: In this study, low RBC count was seen commonly in P. falciparum infected cases $(78.4 \%)$ when compared to cases with mixed infections $(66.6 \%)$ and P. vivax infected cases (53.8\%) whereas, high RBC count was seen mostly in P. vivax $(4.3 \%)$ than in $P$. falciparum infected cases (3.9\%) with respect to P. vivax and P. falciparum species, and there was a good correlation when compared with the study of Thaker MV et al [19].

HCT: Low hematocrit value was common in cases of mixed infection (100\%), followed by P. falciparum (94.2\%) and P. vivax infected cases (67.8\%), and this correlated wells with study done by Ranjini $\mathrm{CY}$ which had similar findings ((P. Vivax-38.8\%, P. Falciparum $-63.6 \%$ and mixed infection $-10 \%)$ [20].

Blood Indices: In the present study, low MCV values was seen mostly in $P$. falciparum infected cases $(78.4 \%)$ when compared to mixed infection $(66.6 \%)$ and P. vivax infected cases (53.8\%), whereas in studies conducted by Ranjini CY [20] and Taha $K$ [21] there was no significant difference between the studied groups of plasmodia.

Reduced $\mathrm{MCH}$ values did not show significant variations between different species of malaria (PV - 36.5\%, PF - 35.2\%, M - 33.3\%) in the present study and this correlated well with studies done by Ranjini CY [20] and Taha K [21], where no significant changes in $\mathrm{MCH}$ value were seen among the different species of malaria.

Low MCHC values were commonly seen in mixed infection cases (33.3\%) when compared to P. vivax 
(22.5\%) and P. falciparum infected cases (19.6\%) in this study, whereas in studies done by Ranjini $\mathrm{CY}$ [20] and Taha $K$ [21], no statistical significant changes were seen among the different species of malaria.

TLC: In the present study, leucopenia was common in P. falciparum infected cases $(47.1 \%)$ when compared to mixed infection (33.3\%) and P. vivax infected cases $(22.6 \%)$. Similar findings were observed in study done by Asif N (P. Vivax-20.3\%, P. Falciparum - $27.4 \%$ and mixed infection $24.9 \%$ ) [22], whereas in study done by Syamsundar B (P. Vivax-26.9\%, P. Falciparum - 25\% and mixed infection $-25 \%$ ), no significant variations were seen among the different species of malaria [23].

Leucocytosis was seen mostly in mixed infection cases $(16.7 \%)$ when compared to P. vivax infected cases $(8.6 \%)$ and P. falciparum (7.8\%) and this had a good correlation with the study done by Asif $\mathrm{N}$ [22] (P. Vivax-7.9\%, P. Falciparum - $8 \%$ and mixed infection $-9.6 \%$ ) whereas No case of leucocytosis was observed in the study conducted by Syamsundar B [23].

DLC: In the present study, neutrophilia was seen more in cases of mixed infection (16.6\%) followed by P. vivax $(11.7 \%)$ and P. falciparum infected cases $(10.7 \%)$, while neutropenia was seen more in $P$. falciparum $(64.7 \%)$ when compared to P. vivax infected cases $(33.3 \%)$.

Lymphocytosis was seen more in P. falciparum $(19.6 \%)$ when compared to mixed infection $(16.6 \%)$ and P. vivax infected cases $(3.2 \%)$ in this study, whereas lymphopenia was seen more in $P$. falciparum $(33.8 \%)$ when compared to mixed infection $(16.6 \%)$ and $P$. vivax infected cases (10.7\%).

There was not much of variation in the eosinophil and monocyte count in P. vivax, P falciparum and mixed infection cases.

All the above findings in the present study corroborated well when compared with study done by Akhtar S [4], neutrophilia was seen more in cases of mixed infection (12.5\%) followed by $P$. vivax $(11.1 \%)$ and $P$. falciparum infected cases $(10.2 \%)$, while neutropenia was seen more in $P$. falciparum $(66.6 \%)$ when compared to P. vivax infected cases $(33.3 \%)$.

Lymphocytosis was seen more in P. falciparum $(17.7 \%)$ when compared to mixed infection
(12.5\%) and P. vivax infected cases (3.7\%), whereas lymphopenia was seen more in $P$. falciparum $(33.3 \%)$ when compared to mixed infection (25\%) and P. vivax infected cases $(11.1 \%)$.

Thrombocytopenia: In this present study, mild degree of thrombocytopenia was mostly seen in $P$. vivax infected cases $(31.2 \%)$ when compared to $P$. falciparum $(25.5 \%)$ and mixed infection cases $(16.6 \%)$ and it correlated well with study done by Bajaj P [24] (P. vivax - 62\%, P. falciparum - 37\%, mixed infection cases $-1 \%$ ), however, in study done by Patel P (P. vivax - 63.6\%, P. falciparum - 68\%, mixed infection cases - 100\%), mild degree of thrombocytopenia exhibited mostly in mixed infection cases, followed by $P$. falciparum and $P$. vivax infected cases [25].

Moderate degree of thrombocytopenia was common in mixed infection cases $(66.6 \%)$ followed by $P$. vivax $(34.4 \%)$ and $P$. falciparum infected cases $(25.5 \%)$ in the present study, whereas in studies done by Patel et al [25] (P. vivax - 9.1\%, P. falciparum - 4\%), P. vivax infected cases mostly showed moderate degree of thrombocytopenia when compared to $P$. falciparum and none in mixed infection cases and by Bajaj P (P. vivax - 19.5\%, P. falciparum $-73.2 \%$, mixed infection cases $-7.3 \%$ ), P. falciparum showed mostly moderate degree of thrombocytopenia when compared to P. vivax and cases of mixed infection [24].

In the present study, severe thrombocytopenia was commonly seen in $P$. falciparum infected cases $(27.5 \%)$ followed by mixed infection $(16.6 \%)$ and $P$. vivax infected cases (9.1\%). This had a good correlation with Bajaj P (P. vivax - 16.7\%, P. falciparum - 58.3\%, mixed infection cases - 25\%) 24 and Patel et al (P. falciparum - 12\%) as they had similar findings in their studies [25]. Whereas, severe thrombocytopenia was seen $19 \%$ of cases [26].

ESR: In the present study, mild rise in ESR was seen most in mixed infection cases (33.3\%), followed by P. vivax (31.1\%) and P. falciparum infected cases (27.4), moderate rise was common in P. vivax infected cases $(51.6 \%)$ when compared to mixed infection (50\%) and P. falciparum infected cases $(45.1 \%)$ and severe rise was seen mostly in $P$. falciparum infected cases (19.6\%) when compared to mixed infections $(16.6 \%)$ and P. vivax infected cases $(8.6 \%)$. 
These findings had a good correlation with the study conducted by Thaker MV et al with respect to $P$. vivax and $P$. falciparum infected cases [19].

Study Limitations: Further study in large number of patients is required to comment regarding changes in haematological profile in early diagnosis of specific species of malaria and further ongoing studies are warranted.

\section{Conclusion}

In conclusion, the relationship between haematological parameters and malarial infection, may afford means to improve diagnosis with specific tests and alleviate clinical severity of or accelerate recovery from this disease. Changes in haematological profile can help in early diagnosis of specific species of malaria for timely and appropriate treatment that can reduce the severity and prevention of additional consequences.

\section{What does the study add to the existing knowledge?}

Literature on changes in haematological profile of specific species of malaria has shown almost neglects other important of specific species early diagnosis and treatment which makes meaningful adding in existing literature by conducting our study to timely recognition and understanding of vital to know and perform hematological investigation to detect early complications and to treat them effectively.

\section{Author's contribution}

Dr. Binita Kanaujia: Study design

Dr. Anand A S: Manuscript preparation

Dr. Sagar Mhetre: Statistical analysis

\section{Reference}

01. Kathryn NS, Kevin CK and Jay SK. Malaria. Canadian Medical Association Journal. 2004;170(11)1693-1702.

[Crossref]

02. Layla AM, Ahmed AM, Ahmed AB and Mirghani AA. Malaria- Haematological Aspects. Annals of Saudi Medicine. 2002;22(5)372-376.

[Crossref]
03. Haroon H, Fazel PA, Naeem M, Mobin A, Naqvi $\mathrm{AH}$, Makki K. Hide and seek- haematological aspects of malaria - a developing country perspective. J Infect Dev Ctries. 2013;7(3)2739.

[Crossref]

04. Akhtar S, Gumashta $\mathrm{R}$ and Mahore $\mathrm{S}$. Haematological changes in malaria- $A$ comparative study. Journal of Pharmacy and Biological Sciences. 2012;2(4)15-19.

[Crossref]

05. Agravat $\mathrm{AH}$ and Dhruva GA. Haematological changes in patients of malaria. Journal of cell and tissue research. 2010;10(3)2325-2329.

[Crossref]

06. Rasheed A, Saeed S and Khan SA. Clinical and laboratory findings in acute malaria caused by various plasmodium species. Journal of Pakistan Medical Association. 2009;59(3)220-223.

[Crossref]

07. Farogh A, Qayyum A, Haleem A and Ghaffar A. Haematological Abnormalities in Malaria. Biomedica. 2009;25;52-55.

[Crossref]

08. Patel A, Jain S, Patel B and Modi B. Haematological Changes in $P$ Falciparum \& $P$ Vivax Malaria. National Journal of Medical Research. 2013;3(2)130-133.

[Crossref]

09. Kelkar DS, Patnaik MM, Joshi SR. Malarial Hematopathy. J Assoc Physicians India. 2004;52;611-12.

[Crossref]

10. Tangpukdee N, Duangdee C, Wilairatana $P$ and Krudsood S. Malaria Diagnosis- A Brief Review. Korean J Parasitol. 2009;47(2)93-102. [Crossref]

11. Srinivas KB. Rapid diagnosis of Malaria. Journal of Laboratory Medicine. 2003;34(8)602-608. [Crossref]

12. Current Malaria and Diagnosis Trends. 2009. Available from: [Article] [Crossref]

13. Hanscheid T. Diagnosis of malaria- a review of alternatives to conventional microscopy. Clin Lab Haem. 1999;21;235-245.

[Crossref] 
14. Bashawri LAM, Mandil AA, Bahnassy AA, Ahmed MA. Malaria- Haematological Aspects. Annals of Saudi Medicine. 2002;22(5-6)372-77.

[Crossref]

15. Kelkar DS, Patnaik MM, Joshi SR. Malarial Hematopathy. J Assoc Physicians India. $2004 ; 52 ; 6114$.

[Crossref]

16. Niazi GA. Haematological aspect of malaria in a population based hospital, Saudi Arabia. J Egypt Soc Parasitol. 1995;25(3)787-93.

[Crossref]

17. Chandra S, Chandra, H. Role of haematological parameters as an indicator of acute malarial infection in Uttarakhand State of India. Mediterr. J Hematol Infect Dis.

2013;5(1)1-7 [Crossref]

18. Erhart LM et al. Haematological and clinical indices of malaria in a semi immune population of western Thailand. Am J Trop Med. $2004 ; 70(1) 8-14$.

[Crossref]

19. Thaker MV, Baxi S, Doshi VG and Gosalia VV. Haematological changes in Patients of Malaria in Tertiary Care Hospital - A Prospective Study. The Southeast Asian J Case Rep Rev. 2013;2(4)208-211.

[Crossref]

20. Ranjini CY, Murgod R, Wilma DS, Santosh KV. Evaluation and comparison of haematological parameters between Vivax and Falciparum malaria. Int J Pharmacol Biol Sci. 2012;3(4)1120-1128.

[Crossref]
21. Taha K. Haematological Changes in MalariaRelation to Plasmodium Species. Kuwait Med J. 2007;39(3)262-267.

[Crossref]

22. Asif N. Malaria in Shorkot garrison- a four year experience report. Pak J Pathol. 2011;22(2)5864.

[Crossref]

23. Syamsundar B, Venugopal RLS, Prasad D, Sankaraiah K, Reddy RS and Pandit VB. Haematological and biochemical alterations in malaria patients with clinical correlation in a tertiary care hospital. Int J Biomed Res. 2013;4(2)3139-3142.

[Crossref]

24. Bajaj P, Shah BS, Dhooria AK, Gupta M. Thrombocytopenia in patients of Malaria. J Evol Med Dental Sci. 2013;2(29)53375341. [Crossref]

25. Patel P, Patel M, Gamit B, Modi J, Kevadiya S and Padsala $\mathrm{S}$. Thrombocytopenia in malaria: correlation with various prevalent species. International Journal of Medical Science and Public Health. 2013;2(4)945-949. [Crossref]

26. Surve KM, Kulkarni AS, Rathod SG, Bindu RS. Study of haematological parameters in malaria. Int J Res Med Sci. 2017;5;2552-7. [Crossref] 